International Journal of Linguistics, Literature and Translation (IJLLT)

ISSN: 2617-0299 (Online); ISSN: 2708-0099 (Print)

DOI: $10.32996 / \mathrm{ijllt}$

Journal Homepage: www.al-kindipublisher.com/index.php/ijllt

\title{
A Good Computer-assisted Translation Tool Wordfast for PPT Translation
}

Yuan Jie

Student of Translation Studies, School of Languages and Cultures, The University of Sheffield, UK

Corresponding Author: Yuan Jie, E-mail: jyuan22@sheffield.ac.uk

\section{ARTICLE INFORMATION}

Received: December 08, 2020

Accepted: February 14, 2021

Volume: 4

Issue: 2

DOI: 10.32996/jillt.2021.4.2.1

\section{KEYWORDS}

CAT; Wordfast; Translation;

Terminology; Procedures

\section{ABSTRACT}

As China develops very fast, it becomes an attractive market for foreign enterprises. A large number of documents such as technical instructions, product manuals, company websites need to be translated. High-equality translations are needed. Computeraided translation is on the rise since it can improve translation quality and efficiency. Wordfast Pro as the second most widely used CAT tools after SDL Trados gets little attention for translators in China. After comparing some features of three computerassisted translation tool: wordfast, SDL Trados and Memsource, it is found that Wordfast is easier to handle for PPT translations from English to Chinese. This paper will illustrate the translation procedures, problems and some recommendations using Wordfast. Through analysis of empirical studies of some instruction translation of PPT files, the author has proved the advantages of wordfast in dealing with PPT file in terms of interface, terminology management, translation omissions and network dependency. After reviewing the translation procedures and problems, it will facilitate those translators who intend to start using Wordfast and know more about it and speed up the translators' work. Based on the current user experience, some recommendations for the software developers are also put forward which is of practical significance to improve the quality of CAT software. The suggestions for communication between clients and translators can improve the efficiency and make both sides feel satisfied.

\section{The advantage of CAT in the practice of translating instructions}

According to Chan (2016, p.310), as technology is increasingly used in translation practice, translation needs to be redefined "from the traditional to the technological" and translators need to evolve "from craftsman to technologists". CAT has great significance in translating technical instructions. The language of instruction is objective with lots of terms. CAT tools can maintain the format consistency, avoid translation omissions, deal with word repetition efficiently and maintain terminology consistency.

\section{Wordfast as a translation aid}

After comparing with Memsource and SDL, Wordfast Pro 5 is chosen for translating PPT file. Memsource as a web-based tool is dependent on internet connection. Compared with Trados, wordfast has more advantages for translating PPT file. Firstly, the terminology management tool Multiterm needs more time to be set up while the glossary of Wordfast can be saved as a tabdelimited text file which is created in excel and saved as Unicode. Secondly, Wordfast has a Live preview function.

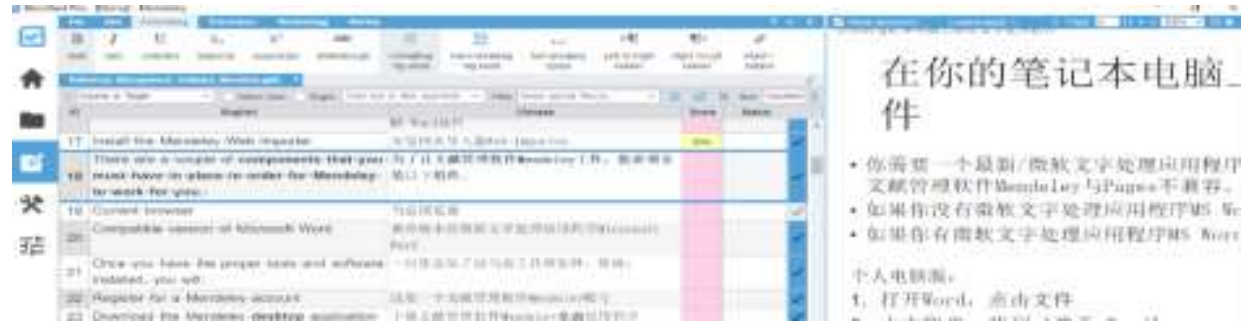

Figure 2-1 wordfast preview

K C AL-KINDI CENTER R D FOR RESEARCH AND DEVELOPMENT Your gateway to world-class research

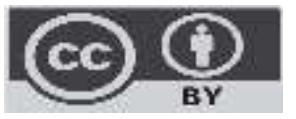

Published by Al-Kindi Center for Research and Development. Copyright (c) the author(s). This open access article is distributed under a Creative Commons Attribution (CC-BY) 4.0 license 


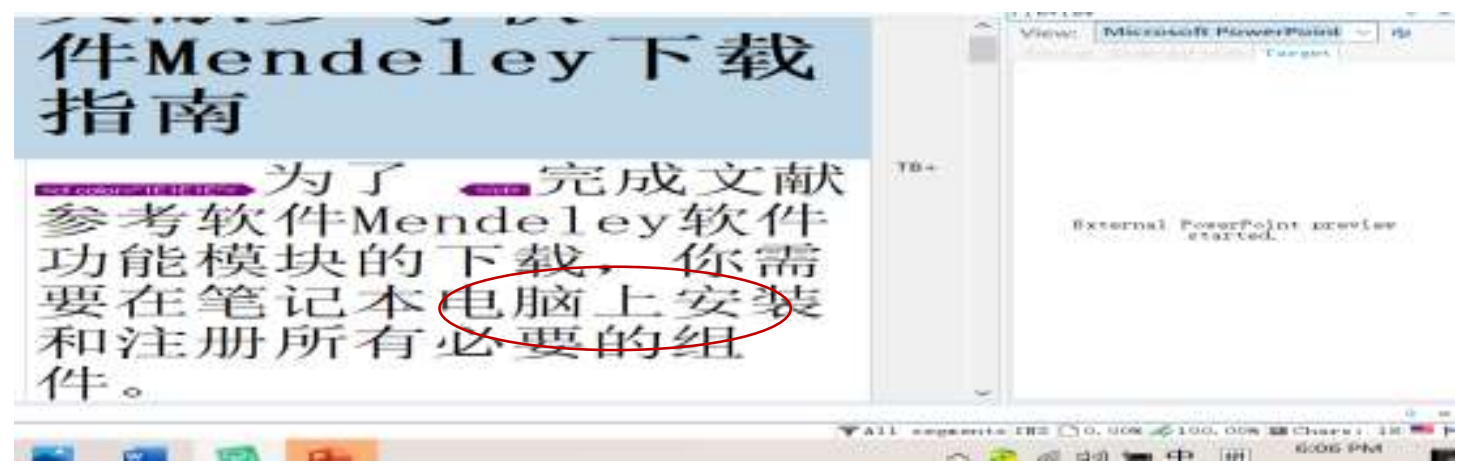

Figure 2-2 Trados External preview

Finally, when adding PowerPoints to CAT tools, wordfast will show all the contents including notes while translators need to tick the choice to include the notes when importing the file in Trados and Memsource. Sometimes it will lead to translation omissions.

\section{Translation procedures}

Melby (1982, p.215) has promoted the concept of multi-level translation aids and divided the translation process into three levels, "ranging from simple text processing to terminology aids to full machine translation." Wordfast obeyed this procedure and it can be simplified as follows:

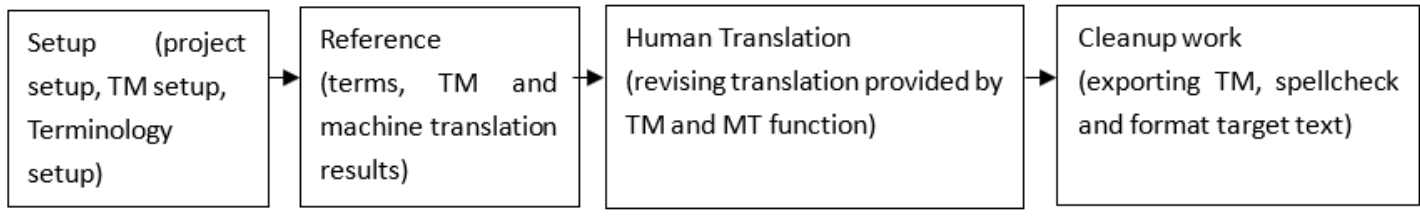

\section{1 Creating a project}

The first step for individual translator is to create a project.

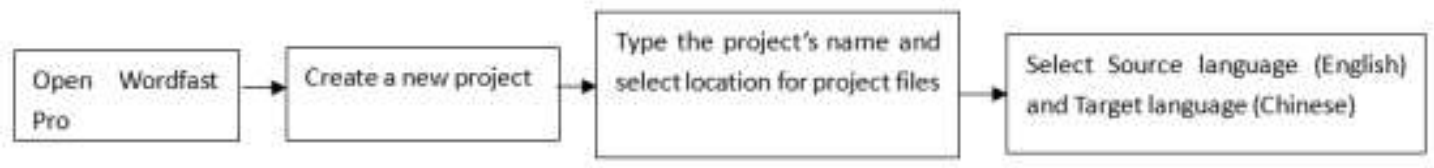

Then the project subfolders are created as follows:

01_source is to save the file from the client. 02_tm is to save the translation memory. 03_glossary is to save the glossary file. 04_target is to save the translation files. 05_project is to save the files generated from the project and 06_out is to save all the files back to the client.

After creating the project, wordfast can analyze the file and generate a report.

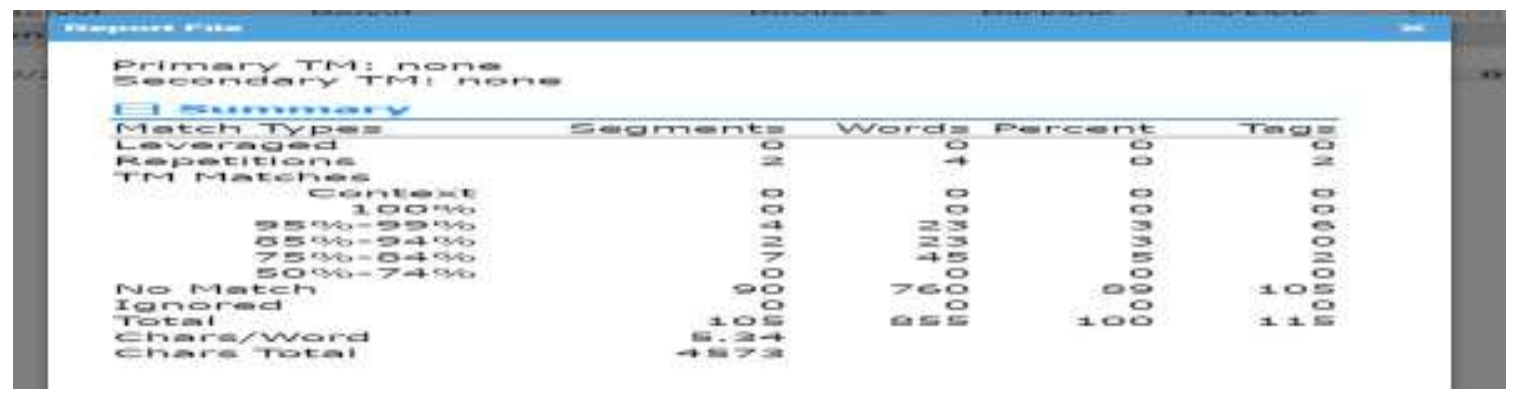

Figure 3-1 Wordfast analysis report 
The translator can get a general idea about the task, issue an invoice and set up a reasonable schedule based on the analysis report.

\subsection{Creating translation memory}

Bowker (2002) referred that translation memory plays an important role in formulating the texts to maximize their potential for reuse. Translation memory not only saves time for translators who can focus on new translation instead of translating identical content but also provides clients and translators with consistent terms.

The procedure for creating translation memory is as follows:

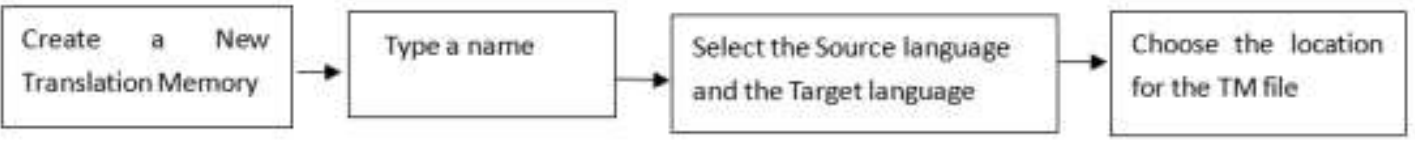

This new TM is ready to use and make sure this TM can be writable so that it can be updated when doing translation.

\subsection{Creating a terminology bank for the translation task}

Peter Newmark (1988, p.151) put forward the importance of terminology translation: "technical translation is primarily distinguished from other forms of translation by terminology, although terminology usually only makes up about 5-10\% of a text." Zachary (1979) also referred that inconsistency of terms is the major reason for rework.

Wright (1997, p.13) defined the term as "the words that are assigned to concepts used in special languages that occur in subjectfield or domain-related texts." Words used in special area can be selected as terms. Wright (1997, p.14) also set up criteria for selecting terms and specify different kinds of terminological units: single-word and multiword terms, set phrases, collocations, standard texts, abbreviated forms of terms or compound terms so abbreviation form of terms are also included in terminology bank. According to Collet (2004), term has two functions: the naming function and cohesion producing function. Zachary (1979) put forward that terminology translation becomes a bigger problem in technical vocabulary translation because of different meaning of the polysemy in different fields. Besides there are also lots of metaphors used in scientific terminology so that the translator needs to detect them by analyzing the context or the semantic content. For example, Terms like "menu" is not a real menu and "Window" is not a real window in software field. The meanings of these kinds of terms should be detected by combining the context.

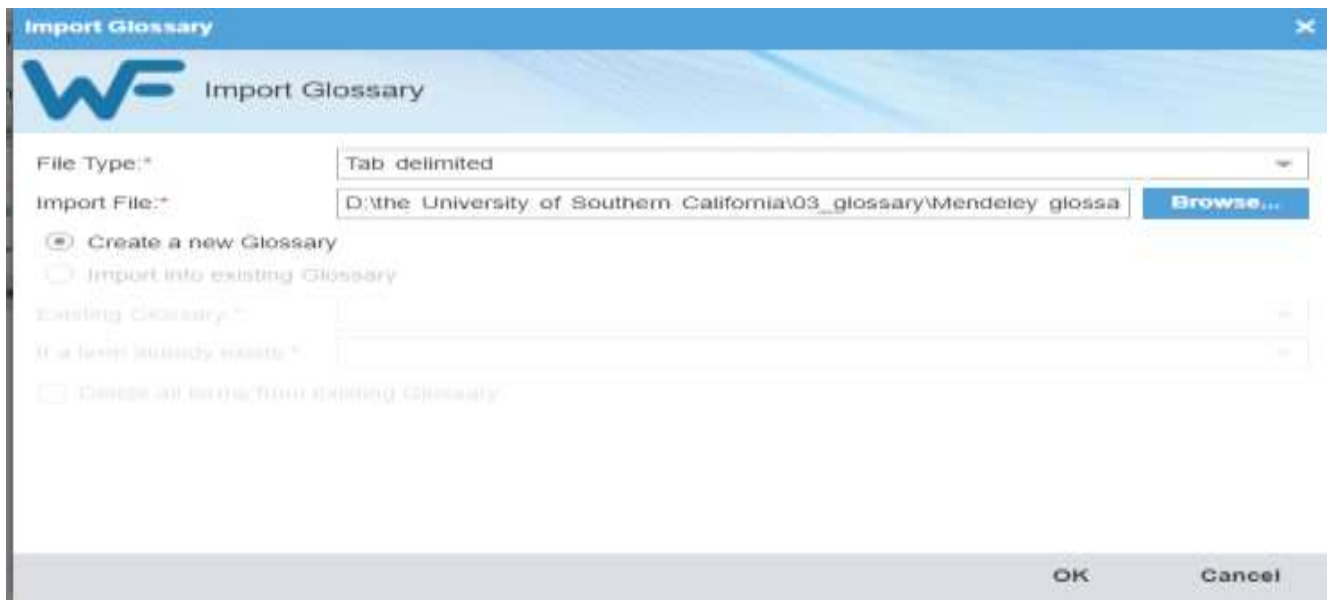

Figure 3-2 Import Glossary

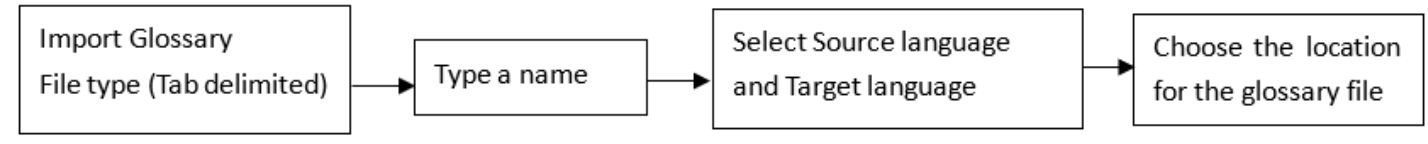

After adding the terms translators can edit them in Glossary Editor. 


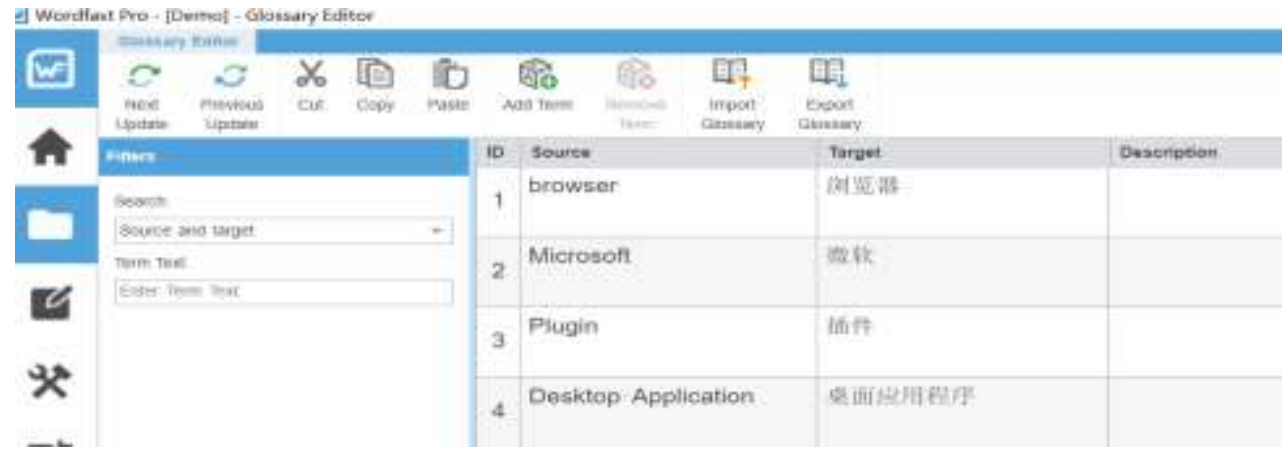

Figure 3-3 Glossary Editor

\subsection{Preference settings}

The translator can customize the behavior of Wordfast in the respect of auto-propagation and auto-suggestion. It is advisable to use MS Office as spellchecker. WordLingo is the only free MT system available and check "Enable WordLingo" and then finish defining all the necessary settings.

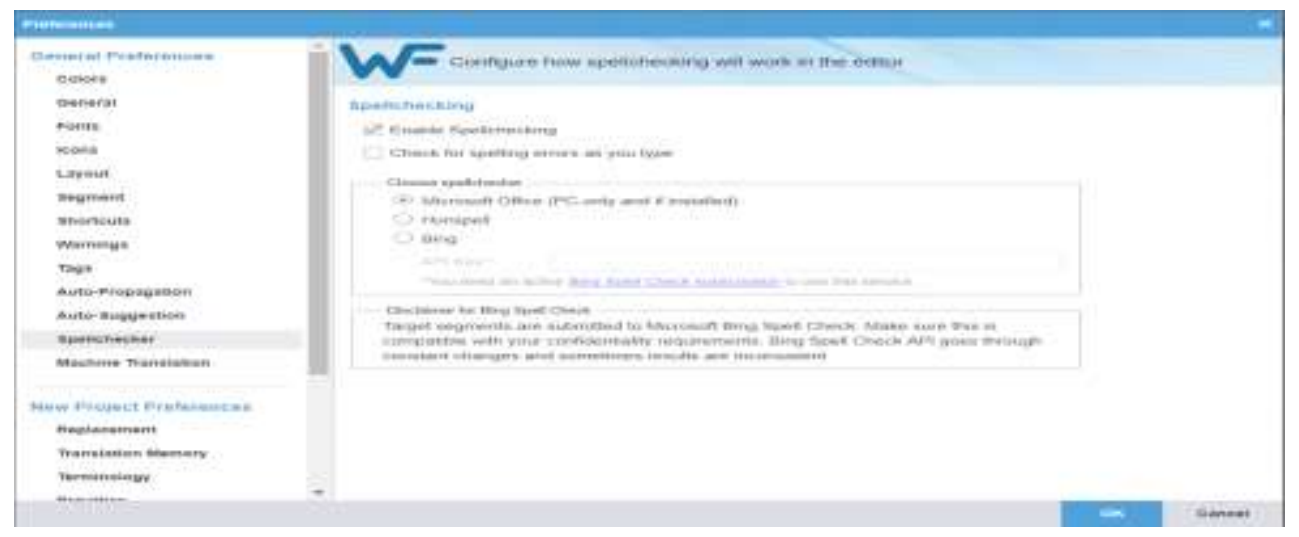

Figure 3-4 Preference setting

3.5 Translating the file

The file can be added or dragged into the workplace.

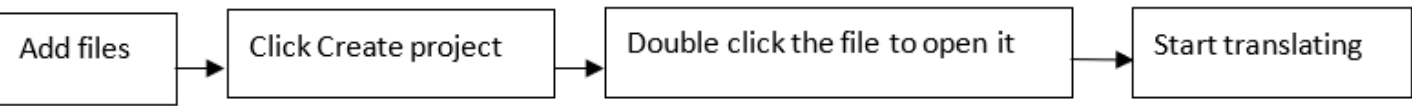

Wordfast can be connected to machine translation, such as Google Translate, Microsoft translate and WordLingo. WordLingo can be used for free. It is very helpful to provide a reference for the translator, especially when there is no TM match.

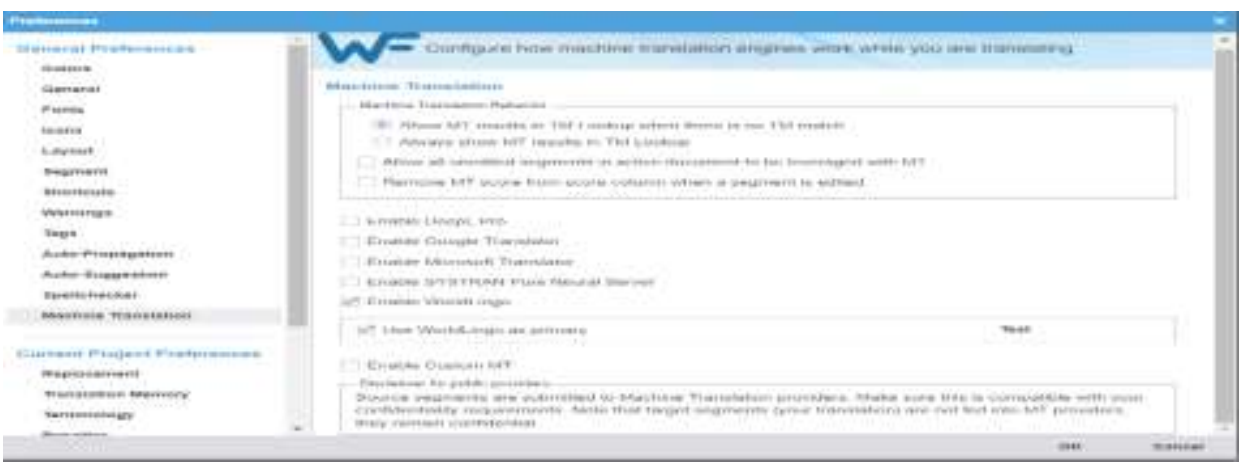

Figure 3-5 Enable WordLingo 
However, this function should be used carefully because translators need to abide by the confidentially policies of the clients.

\section{Spellcheck, quality check and export files}

Go to Review to run Spellcheck and Transcheck after translation. Correct or ignore warnings according to the report.

\section{Project TransCheck Report}

\section{Report Summary (1 files)}

\section{File Name}

Reference_Management_Software_Mendeley.pptx.txif

Figure 4-1 Transcheck report

Export TM, target file and other project files in case the client need them. Make sure the translated file has the same formatting as the source file.

\section{Problems in the translation task}

\subsection{Merge segments}

Before translating, some segments need to be merged or split.

Next is an example about one sentence split into two segments.

\begin{tabular}{l|l}
\hline 98 & The Mendeley icon will \\
\hline 99 & show up in the top right corner of your browser.
\end{tabular}

Go to Translation tab, select the segment and click Merge. The status will be denoted with an icon.

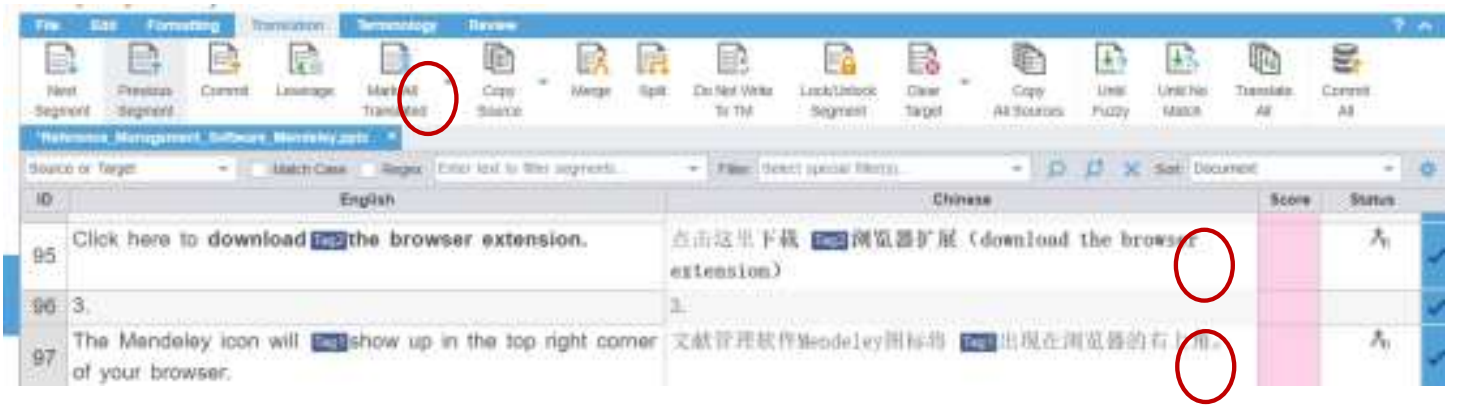

\subsection{Batch change terms}

When the term needs to be replaced with a better translation, use Find/Replace to search for and replace text so that the terms can keep consistency.

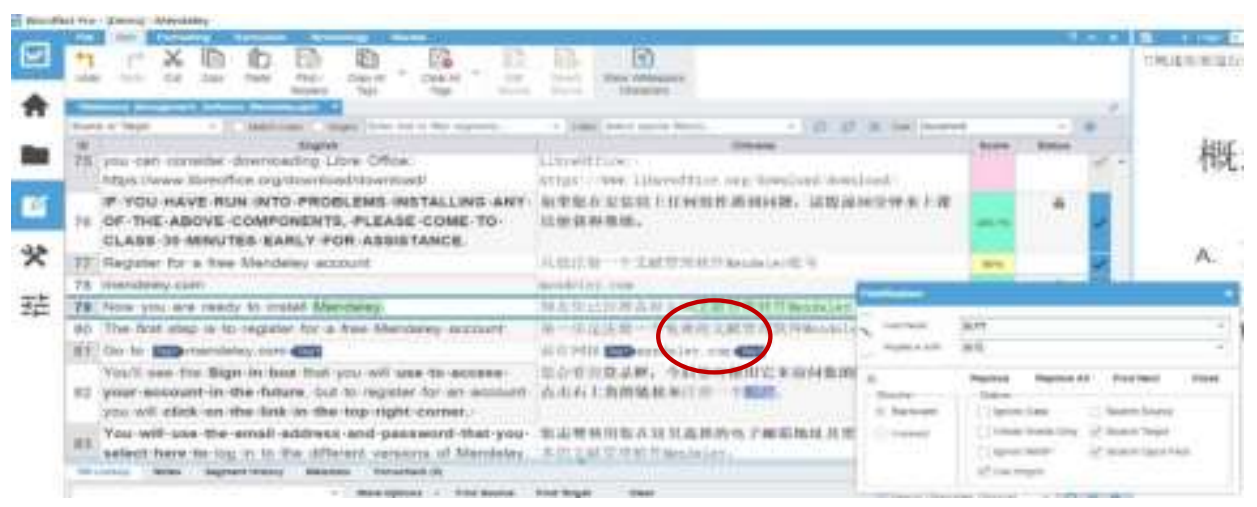

Figure 4-2 Change terms with a better translation 


\subsection{Format adjustment of target text}

The format of the target file needs to be adjusted because of different length between source language and target language. This problem is solved by manually adjusting the format.

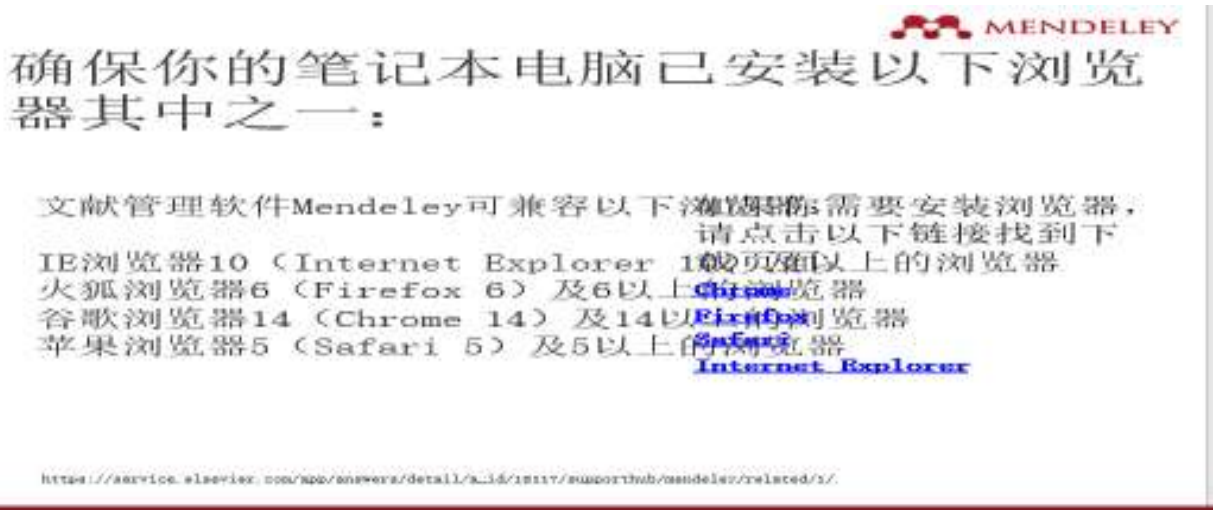

Figure 4-1 Original format

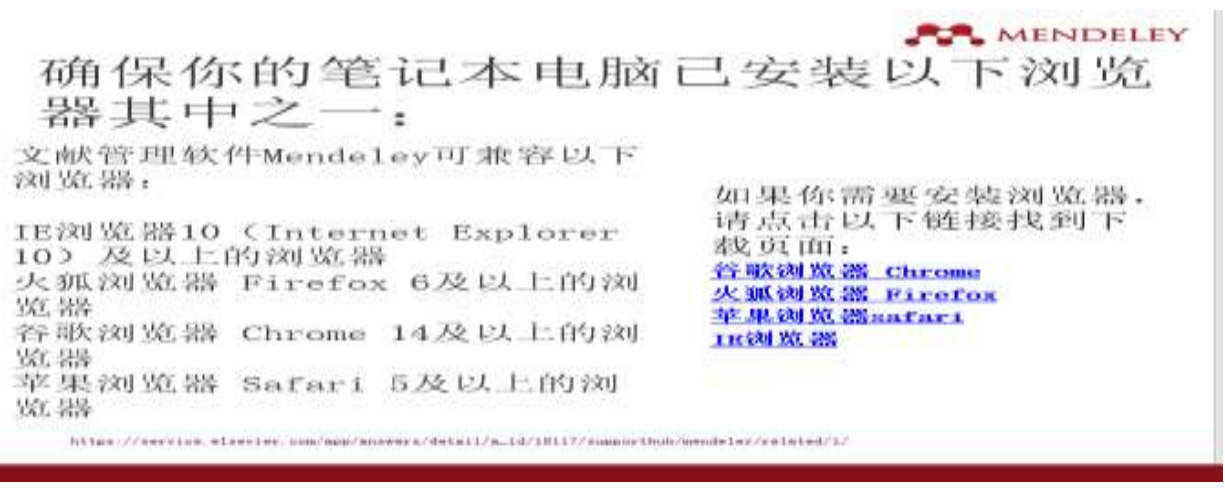

Figure 4-2 format after adjustment

\subsection{Edit source text}

The source text has some inconsistent terms, such as Microsoft \& Mircrosoft or MS word plugin \& MS word plug in. Go to Edit tab and click Edit Source and then replace the error with correct words.

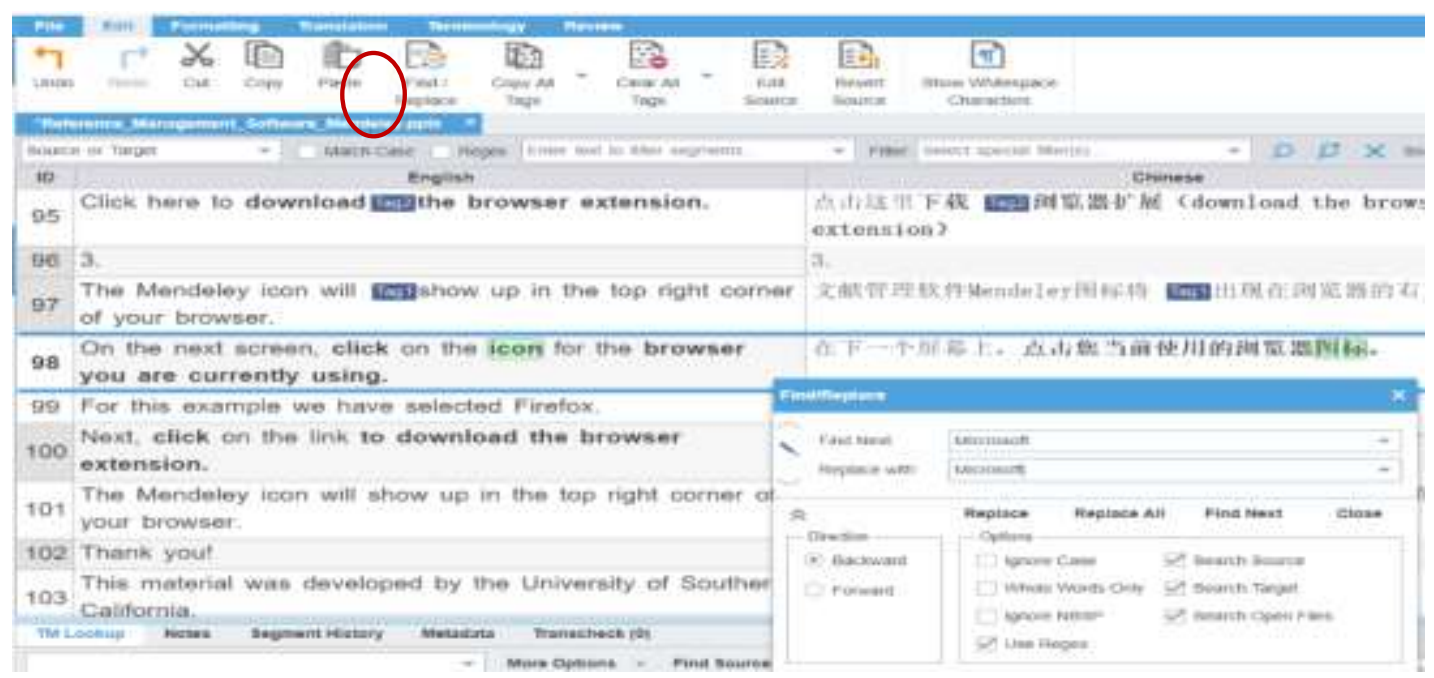

Figure 4-1 Change source text error 


\section{Conclusion and recommendation}

CAT tools help translators produce better translation and they are still evolving and developing. Through analysis of advantages of wordfast in translating PPT files with simple terminology management, its MS Word interface and short learning curve, translators can have more options to do translation jobs. Since wordfast can be compatible with different file formats, such as MS Office, PDF, HTML, SDL Trados Xliff, FrameMaker with the feature of easy access and easy to learn, Wordfast can be taught in China in the translation courses.

As for the future development of CAT, there are also some suggestions.

Terminology bank needs improvement. Wordfast cannot recognize various word forms of a same word so other forms are not considered as terms. For example, Microsoft Word can't be identified as the same term with MS Word.

\section{Install MS |Word (if necessary) 68 Microsoft Word 2011 and 2016.}

On the other hand, TM technology has defects in determining match rate. Minor details such as word forms, tags or punctuations will reduce match rate. The tag difference causes the reduction of match rate.

\begin{tabular}{|c|c|c|}
\hline souree & Target & seore \\
\hline Downioad the Mendeley desktop application & 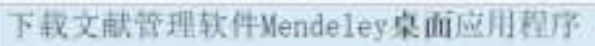 & $100+\%$ \\
\hline $\begin{array}{l}\text { Downioad the Mendeley deshieigdesktop } \\
\text { application }\end{array}$ & 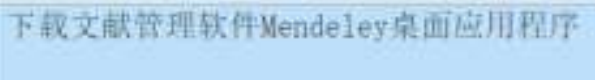 & $99 \%$ \\
\hline
\end{tabular}

There are some recommendations for the clients, such as terms consistency of the source text, using "Query Template" to reduce back-and-forth communication, providing TM or reference materials if they have and informing whether the document is confidential or not before translation. Therefore, the translation quality can be greatly improved and the client feel satisfied.

However, this study has some limitations. On the one hand, comparisons among different CAT tools are not abundant. Therefore, in order to guide the translators to choose different CAT tools, the advantages and disadvantages can be discussed in depth. On the other hand, machine translation functions are not discussed in detail since this function is linked to the MT server and most of them need licenses. It will be significant if the studies can combine MT function and CAT translation with abundant texts analysis.

Studies on CAT evaluations are scarce. This study can provide some usage guidance for translators but lack of guidance for the evaluation. After the studies on CAT tools usage, some emphasis can be put on evaluation both on MT and CAT.

Query Template is as follows:

\begin{tabular}{|l|l|l|l|l|l|}
\hline Date & Project & Source file & Source term & Problem \\
\hline $\begin{array}{l}\text { December, } \\
2020\end{array}$ & $\begin{array}{l}\text { The } \\
\text { University of } \\
\text { Southern } \\
\text { California }\end{array}$ & $\begin{array}{l}\text { Reference_Management_ } \\
\text { Software_Mendeley }\end{array}$ & Mendeley & $\begin{array}{l}\text { Can you confirm that } \\
\text { product names remain in } \\
\text { English or be translated } \\
\text { in occurrences like } \\
\text { "COMPANY PRODUCT } \\
\text { Mendeley?" }\end{array}$ \\
\hline & & & MS Word & & \\
\hline & & & Internet Explorer & & \\
\hline & & & Chrome & & \\
\hline & & & Microsoft Office & & \\
\hline & & & $\begin{array}{l}\text { MS word plug in } \\
\text { and MS Word plugin }\end{array}$ & \\
\hline
\end{tabular}




\section{References}

[1] Bowker, L., (2002). Computer-aided translation technology: a practical introduction. Ottawa: University of Ottawa Press.

[2] Collet, T., (2004). What's term? An Attempt to Define the Term within the Theoretical Framework of Text Linguistics. Linguistica Antverpiensia, 3(1), 99-111.

[3] Melby, A., (1982), Multi-level Translation Aids in a Distributed System, Proceedings COLING-82, North-Holland Publishing Company.

[4] Newmark, P. A., (2001). A Textbook of Translation. Shanghai: Shanghai Foreign Language Education Press.

[5] Sin-wai.C. (2017). The future of translation technology: towards a world without Babel. London and New York: Routledge.

[6] Wayne, Z. (1979). A Survey of Approaches and Issues in Machine-Aided Translation Systems. Computers and the Humanities. 13(1)

[7] Wright, S. \&G. Budin(eds). (1997). Handbook of Terminology Management. Amsterdam/Philadelphia: John Benjamins Publishing Company. 